Brief Report

\title{
Commensal Neisseria Are Shared between Sexual Partners: Implications for Gonococcal and Meningococcal Antimicrobial Resistance
}

\author{
Christophe Van Dijck ${ }^{1}{ }^{\mathbb{D}}$, Jolein G. E. Laumen ${ }^{1}$, Sheeba S. Manoharan-Basil ${ }^{1}$ \\ and Chris Kenyon 1,2,*iD \\ 1 Department of Clinical Sciences, Institute of Tropical Medicine Antwerp, 2000 Antwerp, Belgium; \\ cvandijck@itg.be (C.V.D.) \\ 2 Department of Medicine, University of Cape Town, Cape Town 7700, South Africa \\ * Correspondence: ckenyon@itg.be
}

Received: 22 February 2020; Accepted: 16 March 2020; Published: 19 March 2020

\begin{abstract}
Antimicrobial resistance in pathogenic Neisseria parallels reduced antimicrobial susceptibility in commensal Neisseria in certain populations, like men who have sex with men (MSM). Although this reduced susceptibility can be a consequence of frequent antimicrobial exposure at the individual level, we hypothesized that commensal Neisseria are transmitted between sexual partners. We used data from a 2014 microbiome study in which saliva and tongue swabs were taken from 21 couples (42 individuals). Samples were analyzed using $16 \mathrm{~S}$ rRNA gene sequencing. We compared intimate partners with unrelated individuals and found that the oral Neisseria communities of intimate partners were more similar than those of unrelated individuals (average Morisita-Horn dissimilarity index for saliva samples: 0.54 versus 0.71 , respectively $(p=0.005)$; and for tongue swabs: 0.42 versus 0.63 , respectively $(p=0.006)$ ). This similarity presumably results from transmission of oral Neisseria through intimate kissing. This finding suggests that intensive gonorrhea screening in MSM may, via increased antimicrobial exposure, promote, rather than prevent, the emergence and spread of antimicrobial resistance in Neisseria. Non-antibiotic strategies such as vaccines and oral antiseptics could prove more sustainable options to reduce gonococcal prevalence.
\end{abstract}

Keywords: commensal; Neisseria; gonorrhea; meningitidis; kissing; sharing; microbiome; transmission; antimicrobial resistance

\section{Introduction}

Neisseria gonorrhoeae has rapidly acquired resistance to all antimicrobials used to treat it, and there is a real risk that it may be untreatable in the near future [1]. It is increasingly appreciated that a key way it acquires this antimicrobial resistance (AMR) is via taking up resistance genes from oropharyngeal commensal Neisseria. The genus Neisseria is one of the three most abundant phyla in the human oral microbiome [2], with almost all individuals being colonized with at least one Neisseria species [3]. This high prevalence, in combination with extensive antimicrobial exposure, is thought to explain the extensive AMR in commensal Neisseria that has been found in certain populations, like cohorts of men who have sex with men (MSM) [4] and that has played an important role in the genesis of AMR in N. gonorrhoeae [5].

Epidemiological and modeling studies evaluating the emergence of AMR in N. gonorrhoeae have typically included the sexual transmission of resistant gonococci but not commensal Neisseria [6,7]. If resistant commensal Neisseria were also sexually transmitted, this would be important to take into consideration. This would be particularly important if these commensals could be transferred via highly prevalent activities such as tongue kissing. Transfer via kissing would diminish the likelihood 
that traditional gonorrhea control measures would work to control the genesis and spread of gonococcal AMR. In certain instances, they may even be counterproductive. Several authors have, for example, suggested that because pharyngeal gonorrhea plays such an important role in the emergence of AMR (via horizontal gene transfer from commensals), intensive screening and treatment of pharyngeal gonorrhea in MSM should be advocated [1]. This strategy has been shown to result in extremely high antimicrobial exposure with a resultant high probability of inducing AMR in commensal Neisseria [8]. If these resistant Neisseria were then transferred via kissing and these resulted in AMR in N. gonorrhoeae, then intensive screening may indirectly increase rather than decrease the probability of gonococcal AMR emergence.

Concerns around the transmission of commensal Neisseria via kissing have emerged following increasing evidence of this mode of transmission for related bacteria. Several studies have found that kissing is a risk factor for meningococcal disease [9-11] or carriage [12-15] among students. Likewise, $N$. gonorrhoeae can be readily cultured from saliva [16-18], saliva use as a lubricant is a risk factor for rectal gonorrhea [19], kissing [20-22] as well as having a main partner with pharyngeal gonorrhea [23] may be risk factors for pharyngeal gonorrhea and a mathematical transmission model showed that oro-oral transmission is essential to generate the actual prevalence of gonorrhea among MSM [6].

Furthermore, a number of studies have found that the oral microbiome is shared between household members [24,25]. An important study by Kort et al. in 2014 demonstrated that intimate partners share a similar oral microbiome and that the degree of similarity of the salivary microbiota correlates with the kissing-frequency in the past weeks and with the time since the last kiss [26]. They calculated that an intimate kiss of 10 seconds leads to an average transfer of $10^{8}$ bacteria from one partner to another [26].

These considerations led us to hypothesize that commensal Neisseria are transmitted between sexual partners. To test this hypothesis, we performed a secondary analysis of the study by Kort et al. We found that kissing partners shared more similar Neisseria communities than unrelated individuals.

\section{Results}

The dataset provided by Kort et al. [26] consisted of tongue and salivary microbiota samples taken from 21 couples visiting a Zoo in 2012. We compared the results from the entire range of 3000 operational taxonomic units (OTUs) with those from the 66 OTUs which represent members of the genus Neisseria. We found that pairwise comparison of samples using the Morisita-Horn dissimilarity index (MHi) did not differ significantly for analyses based on the entire versus the restricted dataset. Based on Neisseria-related OTUs we found the following:

1. A high pairwise similarity (an MHi value close to zero) between duplicate samples of an individual's tongue surface (MHi 0.17) and saliva (MHi 0.28) indicated that sampling was reproducible at the level of the genus Neisseria (Figure 1).

2. Partners' oral Neisseria communities sampled after a 10-second kiss were not more similar than before the kiss (saliva: average MHi 0.55 before versus 0.53 after, $p=0.704$; surface of the tongue: average MHi 0.39 before versus 0.45 after, $p=0.597$; Figure 1). Therefore, samples before and after kissing were combined in the subsequent analyses.

3. Partners' oral Neisseria communities were more similar compared to unrelated individuals. This was found for saliva (average MHi 0.54 versus 0.71 , respectively, $p=0.005$ ) and for samples of the tongue surface (average MHi 0.42 versus 0.63 , respectively, $p=0.006$; Figure 1 ). 


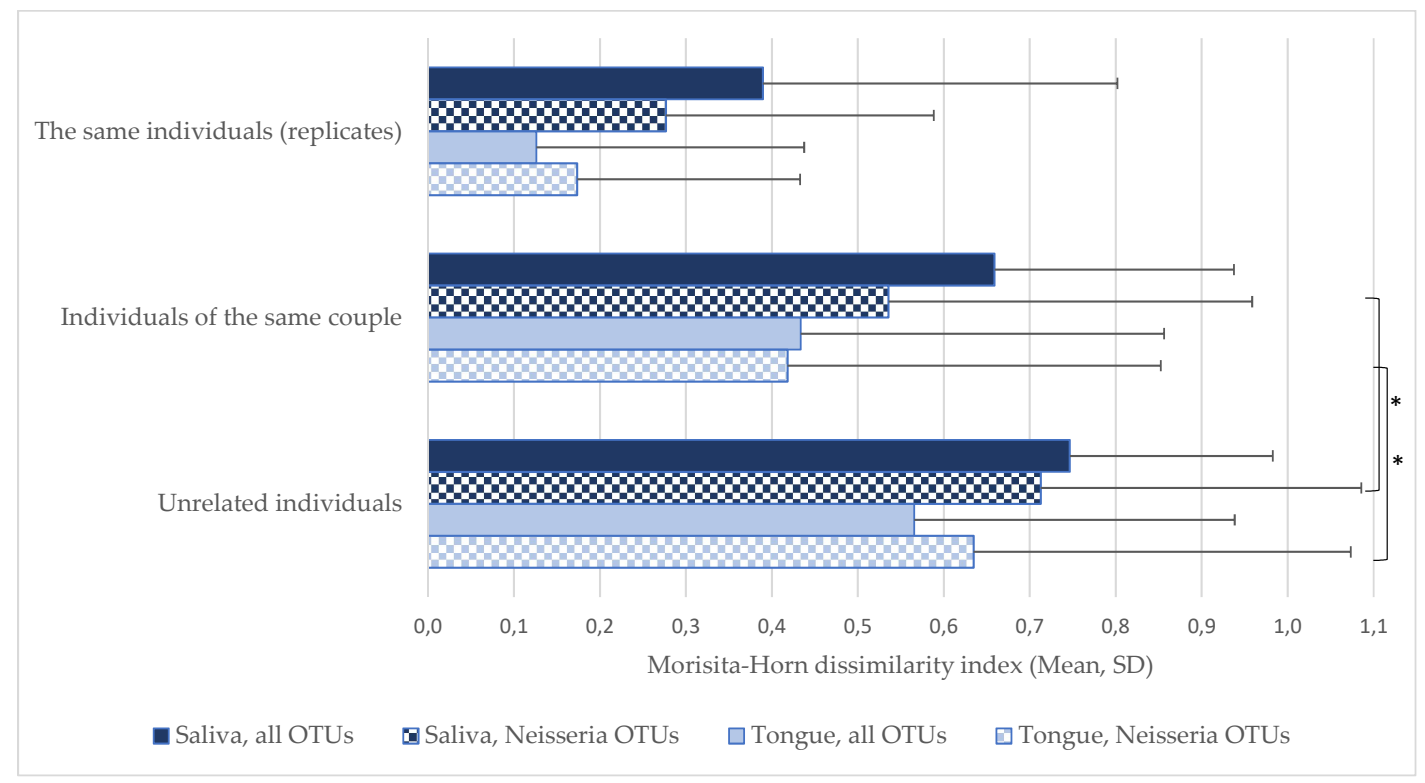

Figure 1. Morisita-Horn dissimilarity indices of samples from the same individuals, intimate partners and unrelated individuals. An index of 0 represents complete similarity whereas an index of 1 means complete dissimilarity. Each bar shows the average Morisita-Horn index, whiskers indicate standard deviations, ${ }^{*} p<0.01$.

\section{Discussion}

Although it was already known that household members and intimate partners share oral commensal microbiota [24-26], the current analysis demonstrates that intimate partners also share similar commensal Neisseria. This is a logical, yet important finding, as commensal Neisseria are known to harbor several AMR determinants [27] that are a frequent source of AMR for pathogenic Neisseria $[4,28,29]$.

Sharing of commensal Neisseria via this and other modalities may, therefore, explain the high prevalence of antimicrobial resistant commensal Neisseria in certain groups of patients. A study from Japan in 2005-2006, reported the antimicrobial susceptibility of 45 oropharyngeal Neisseria subflava isolates from men with urethritis and female commercial sex workers. The majority of isolates had reduced susceptibility to penicillin, tetracycline and ciprofloxacin [30]. Another study in Vietnam in 2016-2017 investigated 265 Neisseria isolates from 207 MSM, including 9 gonococci and 13 meningococci. Ten different Neisseria species were identified. Twenty-eight percent of samples had reduced susceptibility to ceftriaxone (minimum inhibitory concentration $\geq 0.125 \mathrm{mg} / \mathrm{L}$ ) [4]. The reason for the high prevalence of commensal Neisseria with reduced antimicrobial susceptibility in these groups of patients presumably parallels the one proposed for gonorrhea: repeated cycles of reinfection/recolonization and antimicrobial exposure in individuals within a highly connected transmission-network [31].

In addition, since the pharynx is the predominant reservoir of nonpathogenic Neisseria in humans, it is probable that Neisseria are transmitted between partners by transfer of saliva, either directly (by intimate kissing or through aerosolized droplets), or indirectly (e.g., through shared fomites). The scarcity of nonpathogenic Neisseria within other bodily niches makes it unlikely that the skin, genital or anorectal site act as an intermediate in this transfer process. As already noted, different types of evidence suggest that pathogenic Neisseria species can be transmitted by kissing [6,9-23]. Our findings support to the idea that the genus Neisseria can be transmitted by kissing.

The limitations of this study include the following. First, the fact that partners share certain microbiota does not provide direct evidence of transmission between them. Intimate kissing may be one explanation, but we have not explored alternative means of transmission. Potential mediators of 
transmission could be via fomites or animals (such as pets), or influences on the oral microbiota by environmental factors, common diet or simultaneous exposure to pathogens, toxins, mouthwashes or antimicrobials [32]. Second, identification of the oral microbiota in this study was based on the amplification of hypervariable regions V5-V7 of the 16S rRNA gene. This does not allow for the accurate identification of microbiota at the species level, nor does it provide information concerning antimicrobial susceptibility of the microbiota involved. Still, it seems reasonable to infer that sharing of specific OTUs represents sharing of a specific subset of bacterial genomes and, thus, AMR determinants within these bacteria.

The significance of this study lies in its relevance for preventing the further emergence of AMR in $N$. gonorrhoeae and N. meningitidis. If commensal Neisseria can be spread by common-place activities such as kissing, then this increases the probability that intensive gonorrhea screening in high prevalence populations such as MSM will, via increased antimicrobial exposure, promote, rather than retard, the emergence of AMR in Neisseria. Certain groups of at-risk populations are frequently exposed to antibiotics to treat symptomatic sexually transmitted infections. Treatment of asymptomatic cases increases this exposure even more. As most cases of anorectal and pharyngeal gonorrhea are asymptomatic, regular screening of asymptomatic patients results in a much higher number of diagnosed infections and, thus, a substantial increase in antibiotic exposure [33]. Currently, several guidelines recommend regular gonorrhea screening among MSM at high risk of infection [34,35]. The idea behind this is that treatment of all cases of gonorrhea in a population would eventually lead to a reduction (or eradication) of the pathogen from that population. There is, however, very little empirical evidence that supports this hypothesis [36]. On the other hand, increased antimicrobial exposure has been linked to AMR in gonorrhea [37,38]. This, together with the finding from the current study that Neisseria (including AMR determinants) may be transmitted to other individuals within a network via kissing, provides another pathway for the dissemination of AMR. Intensive screening and treatment of all positives may have a profound impact on the prevalence of AMR in commensal Neisseria, which could then be rapidly spread between individuals by kissing. A more prudent approach to preventing the emergence of AMR would be to reduce antimicrobial exposure as far as possible. This could include reduced screening and using non-antibiotic strategies such as vaccines and oral antiseptics to reduce gonococcal prevalence $[39,40]$.

\section{Materials and Methods}

\subsection{Sample Collection and Processing}

In the study by Kort et al., samples were collected from 42 individuals (21 couples) visiting a Zoo in the Netherlands in 2014. A swab was taken from the anterior dorsal surface of the tongue and saliva was collected in a sterile $15 \mathrm{~mL}$ tube. Each participant was sampled before and after an intimate kiss of $10 \mathrm{~s}$. Three couples were sampled in duplicate in order to assess reproducibility. Samples were stored at $-80{ }^{\circ} \mathrm{C}$ until further processing. After DNA extraction, quantitative $16 \mathrm{~S}$ rRNA PCR was used to generate an amplicon library based on the $16 \mathrm{~S}$ variable regions V5-V7. Aligned 16S rRNA sequences were clustered into OTUs, defined by $97 \%$ sequence similarity. The RDP Naive Bayesian Classifier and the SILVA reference database (release 119) were used for taxonomic classification. The full study protocol is described in the original paper [26].

\subsection{Availability of Data and Materials}

The dataset supporting the conclusions of this article is available as a supplementary file to the paper by Kort et al. [26] For the Neisseria-specific analysis, the dataset was restricted to only those 66 OTUs representing members of the genus Neisseria. 


\subsection{Assessment of Community Similarity}

Similarity of tongue and salivary microbiota ( $\beta$-diversity) was determined by calculating pairwise distances with the Morisita-Horn dissimilarity index [41] using $R$ version 3.6.1. A value of zero on this index represents complete similarity, whereas a value of one means complete dissimilarity.

\subsection{Statistical Analysis}

The non-parametric Wilcoxon rank-sum test in $\mathrm{R}$ was used to calculate the $p$-values for selected paired differences of data. Data were visualized using Microsoft Excel.

\subsection{Ethics Approval and Consent to Participate}

Not applicable.

Author Contributions: Conceptualization, C.V.D., J.G.E.L. and C.K.; methodology, C.V.D. and C.K.; formal analysis, C.V.D.; writing - original draft preparation, C.V.D.; writing-review and editing, C.V.D., J.G.E.L., S.S.M.-B. and C.K.; visualization, C.V.D. All authors have read and agreed to the published version of the manuscript.

Funding: This research received no external funding.

Conflicts of Interest: The authors declare no conflict of interest.

\section{Abbreviations}

The following abbreviations are used in this manuscript:

AMR antimicrobial resistance

MSM men who have sex with men

OTU operational taxonomic unit

$\mathrm{MHi}$ Morisita-Horn index

\section{References}

1. Wi, T.; Lahra, M.M.; Ndowa, F.; Bala, M.; Dillon, J.A.R.; Ramon-Pardo, P.; Eremin, S.R.; Bolan, G.; Unemo, M. Antimicrobial resistance in Neisseria gonorrhoeae: Global surveillance and a call for international collaborative action. PLoS Med. 2017, 14, e1002344. [CrossRef]

2. Verma, D.; Garg, P.K.; Dubey, A.K. Insights into the human oral microbiome. Arch. Microbiol. 2018, 200, 525-540. [CrossRef]

3. Sâez, J.A.; Carmen, N.; Vinde, M.A. Multicolonization of human nasopharynx due to Neisseria spp. Int. Microbiol. 1998, 1, 59-63. [CrossRef]

4. Dong, H.V.; Pham, L.Q.; Nguyen, H.T.; Nguyen, M.X.B.; Nguyen, T.V.; May, F.; Le, G.M.; Klausner, J.D. Decreased Cephalosporin Susceptibility of Oropharyngeal Neisseria Species in Antibiotic-using Men Who Have Sex With Men in Hanoi, Vietnam. Clin. Infect. Dis. 2019. [CrossRef]

5. Lewis, D.A. The role of core groups in the emergence and dissemination of antimicrobial-resistant $\mathrm{N}$ gonorrhoeae. Sex. Transm. Infect. 2013, 89. [CrossRef]

6. Zhang, L.; Regan, D.G.; Chow, E.P.; Gambhir, M.; Cornelisse, V.; Grulich, A.; Ong, J.; Lewis, D.A.; Hocking, J.; Fairley, C.K. Neisseria gonorrhoeae Transmission among Men Who Have Sex with Men: An Anatomical Site-Specific Mathematical Model Evaluating the Potential Preventive Impact of Mouthwash. Sex. Transm. Dis. 2017, 44, 586-592. [CrossRef]

7. Fairley, C.K.; Cornelisse, V.J;; Hocking, J.S.; Chow, E.P.F. Models of gonorrhoea transmission from the mouth and saliva. Lancet Infect. Dis. 2019, 1-7. [CrossRef]

8. Kenyon, C. We need to consider collateral damage to resistomes when we decide how frequently to screen for chlamydia/gonorrhoea in PrEP cohorts. AIDS 2019, 33, 155-157. [CrossRef]

9. Tully, J.; Viner, R.M.; Coen, P.G.; Stuart, J.M.; Zambon, M.; Peckham, C.; Booth, C.; Klein, N.; Kaczmarski, E.; Booy, R. Risk and protective factors for meningococcal disease in adolescents: Matched cohort study. Br. Med. J. 2006, 332, 445-448. [CrossRef] 
10. Mandal, S.; Wu, H.M.; MacNeil, J.R.; Machesky, K.; Garcia, J.; Plikaytis, B.D.; Quinn, K.; King, L.; Schmink, S.E.; Wang, X.; et al. Prolonged university outbreak of meningococcal disease associated with a serogroup B strain rarely seen in the United States. Clin. Infect. Dis. 2013, 57, 344-348. [CrossRef]

11. Stanwell-Smith, R.E.; Stuart, J.M.; Hughes, A.O.; Robinson, P.; Griffin, M.B.; Cartwright, K. Smoking, the environment and meningococcal disease: A case control study. Epidemiol. Infect. 1994, 112, 315-328. [CrossRef]

12. McMillan, M.; Walters, L.; Mark, T.; Lawrence, A.; Leong, L.E.; Sullivan, T.; Rogers, G.B.; Andrews, R.M.; Marshall, H.S. B Part of It study: A longitudinal study to assess carriage of Neisseria meningitidis in first year university students in South Australia. Hum. Vaccines Immunother. 2019, 15, 987-994. [CrossRef]

13. Van Ravenhorst, M.B.; Bijlsma, M.W.; van Houten, M.A.; Struben, V.M.; Anderson, A.S.; Eiden, J.; Hao, L.; Jansen, K.U.; Jones, H.; Kitchin, N.; et al. Meningococcal carriage in Dutch adolescents and young adults; a cross-sectional and longitudinal cohort study. Clin. Microbiol. Infect. 2017, 23, 573.e1-573.e7. [CrossRef]

14. Neal, K.R.; Nguyen-Van-Tam, J.S.; Jeffrey, N.; Slack, R.C.; Madeley, R.J.; Ait-Tahar, K.; Job, K.; Wale, M.C.; Ala'aldeen, D.A. Changing carriage rate of Neisseria meningitidis among university students during the first week of term: Cross sectional study. Bmj 2000, 320, 846-849. [CrossRef]

15. Marshall, H.S.; McMillan, M.; Koehler, A.; Lawrence, A.; Sullivan, T.; MacLennan, J.M.; Maiden, M.C.; Ladhani, S.N.; Ramsay, M.; Trotter, C.; et al. Impact of meningococcal B vaccine on meningococcal carriage in adolescents. N. Engl. J. Med. 2019, 318-327, in Press. [CrossRef]

16. Hallqvist, L.; Lindgren, S. Gonorrhoea of the throat at a venereological clinic incidence and results of treatment. Sex. Transm. Infect. 1975, 51, 395-397. [CrossRef]

17. Hutt, D.M.; Judson, F.N. Epidemiology and treatment of oropharyngeal gonorrhea. Ann. Intern. Med. 1986, 104, 655-658. [CrossRef]

18. Chow, E.P.; Lee, D.; Tabrizi, S.N.; Phillips, S.; Snow, A.; Cook, S.; Howden, B.P.; Petalotis, I.; Bradshaw, C.S.; Chen, M.Y.; et al. Detection of Neisseria gonorrhoeae in the pharynx and saliva: Implications for gonorrhoea transmission. Sex. Transm. Infect. 2016, 92, 347-349. [CrossRef]

19. Chow, E.P.; Cornelisse, V.J.; Read, T.R.; Lee, D.; Walker, S.; Hocking, J.S.; Chen, M.Y.; Bradshaw, C.S.; Fairley, C.K. Saliva use as a lubricant for anal sex is a risk factor for rectal gonorrhoea among men who have sex with men, a new public health message: A cross-sectional survey. Sex. Transm. Infect. 2016. [CrossRef]

20. Templeton, D.J.; Jin, F.; McNally, L.P.; Imrie, J.C.; Prestage, G.P.; Donovan, B.; Cunningham, P.H.; Kaldor, J.M.; Kippax, S.; Grulich, A.E. Prevalence, incidence and risk factors for pharyngeal gonorrhoea in a community-based HIV-negative cohort of homosexual men in Sydney, Australia. Sex. Transm. Infect. 2010, 86, 90-96. [CrossRef]

21. Cornelisse, V.J.; Walker, S.; Phillips, T.; Hocking, J.S.; Bradshaw, C.S.; Lewis, D.A.; Prestage, G.P.; Grulich, A.E.; Fairley, C.K.; Chow, E.P. Risk factors for oropharyngeal gonorrhoea in men who have sex with men: An age-matched case-control study. Sex. Transm. Infect. 2018, 94, 359-364. [CrossRef]

22. Chow, E.P.F.; Cornelisse, V.J.; Williamson, D.A.; Priest, D.; Hocking, J.S.; Bradshaw, C.S.; Read, T.R.H.; Chen, M.Y.; Howden, B.P.; Fairley, C.K. Kissing may be an important and neglected risk factor for oropharyngeal gonorrhoea: A cross-sectional study in men who have sex with men. Sex. Transm. Infect. 2019, 95. [CrossRef]

23. Cornelisse, V.J.; Zhang, L.; Law, M.; Chen, M.Y.; Bradshaw, C.S.; Bellhouse, C.; Fairley, C.K.; Chow, E.P. Concordance of gonorrhoea of the rectum, pharynx and urethra in same-sex male partnerships attending a sexual health service in Melbourne, Australia. BMC Infect. Dis. 2018, 18. [CrossRef]

24. Song, J.; Lauber, C.; Costello, E.K.; Lozupone, C.A.; Humphrey, G.; Berg-Lyons, D.; Caporaso, J.G.; Knights, D.; Clemente, J.C.; Nakielny, S.; et al. Cohabiting family members share microbiota with one another and with their dogs. eLife 2013, 2013, 1-22. [CrossRef]

25. Abeles, S.R.; Jones, M.B.; Santiago-Rodriguez, T.M.; Ly, M.; Klitgord, N.; Yooseph, S.; Nelson, K.E.; Pride, D.T. Microbial diversity in individuals and their household contacts following typical antibiotic courses. Microbiome 2016, 4, 1-12. [CrossRef]

26. Kort, R.; Caspers, M.; van de Graaf, A.; van Egmond, W.; Keijser, B.; Roeselers, G. Shaping the oral microbiota through intimate kissing. Microbiome 2014, 2, 1-8. [CrossRef]

27. Marangoni, A.; Marziali, G.; Salvo, M.; D'Antuono, A.; Gaspari, V.; Foschi, C.; Re, M.C. Mosaic structure of the penA gene in the oropharynx of men who have sex with men negative for gonorrhoea. Int. J. STD AIDS 2020. [CrossRef] 
28. Igawa, G.; Yamagishi, Y.; Lee, K.I.I.; Dorin, M.; Shimuta, K.; Suematsu, H.; Nakayama, S.I.I.; Mikamo, H.; Unemo, M.; Ohnishi, M.; et al. Neisseria cinerea with high ceftriaxone MIC Is a source of ceftriaxone and cefixime resistance-mediating penA sequences in Neisseria gonorrhoeae. Antimicrob. Agents Chemother. 2018, 62, 1-5. [CrossRef]

29. Wadsworth, C.B.; Arnold, B.J.; Sater, M.R.A.; Grad, Y.H. Azithromycin Resistance through Interspecific Acquisition of an Epistasis-Dependent Efflux Pump Component and Transcriptional Regulator in Neisseria gonorrhoeae. mBio 2018, 9, 1-17. [CrossRef]

30. Furuya, R.; Onoye, Y.; Kanayama, A.; Saika, T.; Iyoda, T.; Tatewaki, M.; Matsuzaki, K.; Kobayashi, I.; Tanaka, M. Antimicrobial resistance in clinical isolates of Neisseria subflava from the oral cavities of a Japanese population. J. Infect. Chemother. 2007, 13, 302-304. [CrossRef]

31. Kenyon, C.R.; Schwartz, I.S. Effects of sexual network connectivity and antimicrobial drug use on antimicrobial resistance in neisseria gonorrhoeae. Emerg. Infect. Dis. 2018, 24, 1195-1203. [CrossRef] [PubMed]

32. Trinh, P.; Zaneveld, J.R.; Safranek, S.; Rabinowitz, P.M. One Health Relationships Between Human, Animal, and Environmental Microbiomes: A Mini-Review. Front. Public Health 2018, 6, 1-9. [CrossRef] [PubMed]

33. Kenyon, C. How actively should we screen for chlamydia and gonorrhoea in MSM and other high-ST-prevalence populations as we enter the era of increasingly untreatable infections? A viewpoint. J. Med Microbiol. 2019, 68, 132-135. [CrossRef] [PubMed]

34. Tan, D.H.; Hull, M.W.; Yoong, D.; Tremblay, C.; O’Byrne, P.; Thomas, R.; Kille, J.; Baril, J.G.; Cox, J.; Giguere, P.; et al. Canadian guideline on HIV pre-exposure prophylaxis and nonoccupational postexposure prophylaxis. CMAJ 2017, 189, E1448-E1458. [CrossRef] [PubMed]

35. Australian Sexually Transmitted Infection \& HIV Testing Guidelines 2019 for Asymptomatic Men Who Have Sex with Men. Available online: http:/ / www.sti.guidelines.org.au (accessed on 18 March 2020).

36. Ridpath, A.D.; Chesson, H.; Marcus, J.L.; Kirkcaldy, R.D.; Torrone, E.A.; Aral, S.O.; Bernstein, K.T. Screening Peter to Save Paul: The Population-Level Effects of Screening Men Who Have Sex with Men for Gonorrhea and Chlamydia. Sex. Transm. Dis. 2018, 45, 623-625. [CrossRef] [PubMed]

37. Kenyon, C.; Buyze, J.; Spiteri, G.; Cole, M.J.; Unemo, M. Population-Level Antimicrobial Consumption Is Associated With Decreased Antimicrobial Susceptibility in Neisseria gonorrhoeae in 24 European Countries: An Ecological Analysis. J. Infect. Dis. 2019, 8. [CrossRef]

38. Wind, C.M.; De Vries, E.; Schim Van Der Loeff, M.F.; Van Rooijen, M.S.; Van Dam, A.P.; Demczuk, W.H.; Martin, I.; De Vries, H.J. Decreased Azithromycin Susceptibility of Neisseria gonorrhoeae Isolates in Patients Recently Treated with Azithromycin. Clin. Infect. Dis. 2017, 65, 37-45. [CrossRef]

39. Chow, E.P.; Walker, S.; Hocking, J.S.; Bradshaw, C.S.; Chen, M.Y.; Tabrizi, S.N.; Howden, B.P.; Law, M.G.; Maddaford, K.; Read, T.R.; et al. A multicentre double-blind randomised controlled trial evaluating the efficacy of daily use of antibacterial mouthwash against oropharyngeal gonorrhoea among men who have sex with men: The OMEGA (Oral Mouthwash use to Eradicate GonorrhoeA) study protocol. BMC Infect. Dis. 2017, 17, 456. [CrossRef]

40. Paynter, J.; Goodyear-Smith, F.; Morgan, J.; Saxton, P.; Black, S.; Petousis-Harris, H. Effectiveness of a group $b$ outer membrane vesicle meningococcal vaccine in preventing hospitalization from gonorrhea in New Zealand: A retrospective cohort study. Vaccines 2019, 7, 1-11. [CrossRef]

41. Horn, H.S. Measurement of "Overlap" in Comparative Ecological Studies. Am. Nat. 1966, 100, $419-424$. [CrossRef]

(C) 2020 by the authors. Licensee MDPI, Basel, Switzerland. This article is an open access article distributed under the terms and conditions of the Creative Commons Attribution (CC BY) license (http:/ / creativecommons.org/licenses/by/4.0/). 